http://portaldeperiodicos.unisul.br/index.php/EeN/index

\title{
SOBRE A LÓGICA DAS RELAÇÕES ENTRE TQM E INOVAÇÃO: INSIGHTS E PROPOSIÇÕES TEÓRICAS
}

\section{ABOUT THE LOGIC OF RELATIONS BETWEEN TQM AND INNOVATION: INSIGHTS AND THEORETICAL PROPOSITIONS}

\section{EN LA LÓGICA DE LAS RELACIONES ENTRE TQM E INNOVACIÓN: IDEAS Y TEORÍAS PROPUESTAS}

\section{Rodrigo Marques de Almeida Guerra}

Professor do Curso de Administração (Graduação e Especialização) da Universidade de Caxias do Sul (UCS) Doutorando em Administração pela Pontifícia Universidade Católica do Rio Grande do Sul (PUCRS) Endereço: Campus Universitário de Caxias do Sul, Bloco F, sala 401, R. Francisco Getúlio Vargas, n. 1130, CEP 95070-560. Caxias do Sul, RS, Brasil.

Telefone: (54) 3218-2011

E-mail: rmaguerra@ucs.br

\section{Cosmo Severiano Filho [In memoriam]}

Pós-Doutorado Sênior em Administração (Organizational Performance and Manufacturing System) na Universidade Federal de Pernambuco (PROPAD/UFP

\section{Vilmar Antônio Gonçalves Tondolo}

Professor do Programa de Pós-Graduação em Administração da Universidade de Caxias do Sul (UCS). Doutorado em administração pela Unisinos, com estágio doutoral realizado na University of Texas Pan American.

Endereço: Campus Universitário de Caxias do Sul, Bloco F, sala 401, R. Francisco Getúlio Vargas, n. 1130, CEP 95070-560. Caxias do Sul, RS, Brasil.

Telefone: (54) 3218-2011

E-mail: vtondolo@gmail.com

Artigo recebido em 29/09/2015. Revisado por pares em 13/12/2015. Reformulado em 01/12/2015. Recomendado para publicação em 14/11/2015, por Ademar Dutra (Editor Científico). Publicado em 30/12/2015. Avaliado pelo Sistema double blind review.
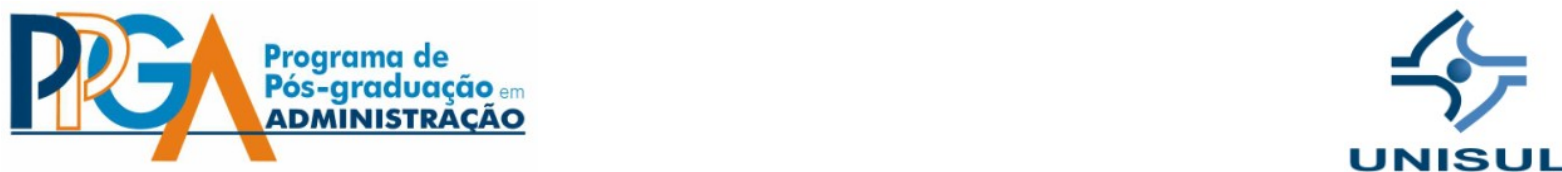


\section{RESUMO}

O presente estudo tem o objetivo principal de compreender, por meio de uma revisão sistemática da literatura, a relação entre TQM e inovação, com o intuito de gerar insights e proposições teóricas. Para isso foram analisados 16 dos 20 principais artigos obtidos da base de dados Scopus por meio dos termos TQM e inovação, além de 23 publicações adicionais, obtidas de forma reversa daquelas revisadas, totalizando 39 textos. Os resultados da pesquisa sugerem que: TQM e inovação possuem diversos pontos convergentes; poucos estudos correlacionam o elemento trabalho em equipe aos cinco tipos de inovação; estudos anteriores associam melhoria contínua à inovação incremental; existem poucas evidências sobre a relação existente entre TQM e inovação radical.

Palavras-chave: TQM; Inovação; Tipos de Inovações.

\section{ABSTRACT}

This study has the main objective to understand, through a systematic literature review, the relations between TQM and innovation, in order to generate insights and theoretical propositions. Thereunto, we analyzed 16 of the top 20 items obtained from Scopus database through the terms TQM and innovation, further 23 additional publications obtained in reverse form from those reviewed ones, a total of 39 items. The survey results suggest that: TQM and innovation have several converging points; few studies correlate the element "teamwork" to the five types of innovation; previous studies have linked continuous improvement to incremental innovation; there is little evidence on the relations between TQM and radical innovation.

Keywords: TQM; Innovation; Types of Innovations.

\section{RESUMEN}

Este estudio tiene el objetivo principal de entender, a través de una revisión sistemática da literatura, la relación entre TQM e innovación, con el fin de generar ideas y propuestas teóricas. Para ello, se analizaron 16 de los 20 artículos obtenidos a partir de la base de datos Scopus por medio de los términos TQM e innovación, además de 23 adicionales de aquellas revisadas, obtenidas de manera inversa de las publicaciones, un total de 39 artículos. Los resultados del estudio sugieren que: TQM e innovación tienen varios puntos de convergencia; pocos estudios correlacionan el elemento de "trabajo en equipo" con los cinco tipos de innovación; estudios anteriores han relacionado la mejora continua de innovaciones incrementales; hay poca evidencia sobre la relación entre TQM e innovación radical.

Palabras-clave: TQM; Innovación; Tipos de innovación. 


\section{INTRODUÇÃO}

Nas últimas décadas, o Total Management Quality (TQM), conhecido no Brasil como Gestão de Qualidade Total ganhou atenção de profissionais, pesquisadores e acadêmicos da área de Qualidade por ser um conceito popular e moderno de gestão (PRAJOGO; SOHAL, 2008). O aumento da concorrência tornou o mercado mais competitivo, exigindo o desenvolvimento de estratégias baseadas, por exemplo, na Filosofia da Qualidade (PEKOVIC; GALIA, 2009), na Teoria da Dependência de Recursos (RDT) (SINGH; POWER; CHUONG, 2011), cultura inovadora (SANTOS-VIJANDE; ÁLVAREZ-GONZÁLEZ, 2007), processo de criação e retenção de conhecimento (LINDERMAN et al., 2004; SHAN; ZHAO; HUA, 2013; TONDOLO; BITENCOURT, 2014), principalmente por empresas de manufatura (AGARWAL et al., 2013).

Não há consenso entre os pesquisadores sobre a relação entre TQM e inovação (ABRUNHOSA; MOURA SÁ, 2008; SADIKOGLU; ZEHIR, 2010; KIM; KUMAR; KUMAR, 2012). A literatura acadêmica sugere que o impacto desta relação depende tanto dos elementos específicos do TQM, quanto dos tipos de inovação (ABRUNHOSA; MOURA SÁ, 2008; PEKOVIC; GALIA, 2009; KIM; KUMAR; KUMAR, 2012).

Desta forma, pode-se afirmar que a relação entre o TQM e a inovação é complexa (PRAJOGO; SOHAL, 2001; ABRUNHOSA; MOURA SÁ, 2008; BON; MUSTAFA, 2013) e ambígua (PRAJOGO; SOHAL, 2001). Sendo assim, é importante confrontar resultados contraditórios (PRAJOGO; SOHAL, 2004) com a finalidade de reavaliar o papel do TQM quanto ao desempenho da inovação (PRAJOGO; SOHAL, 2003). Alguns dos motivos para a discordância entre os pesquisadores podem ser: estudos anteriores terem sido realizados em diferentes contextos, do tipo geográfico, cultural, econômico-financeiro, social, etc. (CALVO-MORA et al., 2014); aplicação de variados métodos (LAGROSEN; LAGROSEN, 2005; VOUZAS; PSYCHOGIOS, 2007; CALVO-MORA et al., 2014); relação diacrônica entre os elementos do TQM, resultados de sua adoção, bem como quanto aos tipos e extensões de seus relacionamentos (FOTOPOULOS; PSOMAS, 2009).

Neste sentido, este trabalho tem o objetivo de compreender, por meio de um ensaio teórico, a relação entre TQM e inovação, com o intuito de gerar insights e proposições teóricas. Com base nisso, o artigo pretende responder ao seguinte problema de 
pesquisa: De que forma pode-se estabelecer melhor compreensão teórica sobre a relação entre TQM e inovação?

\section{REFERENCIAL TEÓRICO}

Esta seção tem o intuito de apresentar uma breve revisão sistemática da literatura sobre TQM e inovação, buscando discutir os seguintes tópicos: práticas do TQM; TQM e inovação; e aspectos convergentes e divergentes entre TQM e inovação.

\subsection{PRÁTICAS DO TQM}

Os princípios do TQM envolvem os seguintes elementos: foco no cliente, visão e comprometimento com a qualidade, melhoria contínua, educação e treinamento, envolvimento e comprometimento da alta administração e funcionários (DEMING, 1990; JURAN, 1993; FEIGENBAUM, 1994; SILAS; EBRAHIMPOUR, 2002). Para efeito deste trabalho e com base na revisão sistemática da literatura, os princípios básicos do TQM estão relacionados aos seguintes componentes: suporte da alta administração (FLYNN; SCHROEDER; SAKAKIBARA, 1994; BUNNEY; DALE, 1997; KAYNAK, 2003; KIM; KUMAR; KUMAR, 2012), envolvimento do funcionário (PRAJOGO; SOHAL, 2001, 2003; KAYNAK, 2003; KIM; KUMAR; KUMAR, 2012), gestão de processos (FLYNN; SCHROEDER; SAKAKIBARA, 1994; SAMSON; TERZIOVSKI, 1999), foco no cliente (IGEL; LAOSIRIHONGTHONG, 2006; SAMSON; TERZIOVSKI, 1999; PRAJOGO; SOHAL, 2001, 2003; trabalho em equipe (SHIBA; GRAHAM; WALDEN, 1997), informação e análise (SAMSON; TERZIOVSKI, 1999; SADIKOGLU; ZEHIR, 2010), melhoria contínua (PRAJOGO; SOHAL, 2001, 2003; KAYNAK, 2003; PERDOMO-ORTIZ; GONZÁLEZ-BENITO; GALENDE, 2006; SADIKOGLU; ZEHIR, 2010), treinamento (SHIBA; GRAHAM; WALDEN, 1997; KAYNAK, 2003; SADIKOGLU; ZEHIR, 2010), gestão da qualidade de fornecedores (AHIRE; RAVICHANDRAN, 2001; KAYNAK, 2003; PERDOMO-ORTIZ, GONZÁLEZBENITO; GALENDE, 2006) e inovação (UTTERBACK; ABERNATHY, 1975; DAMANPOUR; GOPALAKRISHNAN, 1998; HILL; COLLINS, 2000; AHIRE; RAVICHANDRAN, 2001; PRAJOGO; SOHAL, 2001; SINGH; SMITH, 2004; HOANG; IGEL; LAOSIRIHONGTHONG, 2006; SANTOSVIJANDE; ÁlVAREZ-GONZÁlEZ, 2007; ABRUNHOSA; MOURA SÁ, 2008; PINHO, 2008; PEKOVIC; GALIA, 2009; KIM; KUMAR; KUMAR, 2012). Apesar de os estudos sobre TQM parecerem diminuir, acadêmicos e pesquisadores ainda estão entusiasmados com pesquisas 
empíricas sobre o tema (EHIGIE; MCANDREW, 2005). A adoção do TQM promove o desenvolvimento da cultura de inovação das empresas e, além disso, possibilita maior capacidade prática de adoção de inovações em relação à concorrência (SANTOS-VIJANDE; ÁLVAREZ-GONZÁLEZ, 2007). O desenvolvimento coordenado e sistemático do TQM contribui para o condicionamento e alimentação de processos inovadores, possibilitando a excelência do negócio (MELE; COLURCIO, 2006). Neste sentido, a difusão do TQM está aumentando globalmente, podendo ser aplicável às organizações como uma técnica de gestão flexível (EHIGIE; MCANDREW, 2005).

No entanto, a literatura acadêmica não estabelece um consenso sobre os elementos que estimulam a relação entre TQM e inovação. Alguns autores propõem cinco fatores: foco no cliente; liderança e comprometimento da alta direção; formação e educação; equipe; e cultura (DEMING, 1990; JURAN, 1993; FEIGENBAUM, 1994). Outros afirmam que são sete os fatores mais frequentemente investigados sobre TQM e inovação: foco no cliente e satisfação; treinamento; liderança e comprometimento da alta direção; trabalho em equipe; envolvimento dos trabalhadores; melhoria contínua; e informação de qualidade e medição de desempenho (SILAS; EBRAHIMPOUR, 2002).

Outras pesquisas evidenciam alguns elementos que podem interferir nas práticas do TQM: cultura inovadora (MELE; COLURCIO, 2006; SANTOS-VIJANDE; ÁLVAREZ-GONZÁLEZ, 2007), planejamento estratégico (POWELL, 1992), nível de desempenho organizacional e inovação (KAYNAK, 2003; SADIKOGLU; ZEHIR, 2010), práticas da qualidade e inovação (PEKOVIC; GALIA, 2009; KIM; KUMAR; KUMAR, 2012), desempenho da inovação (HOANG; IGEL; LAOSIRIHONGTHONG, 2006), desempenho da qualidade e da inovação (PRAJOGO; SOHAL, 2003; FENG et al., 2006), inovação tecnológica (ABRUNHOSA; MOURA SÁ, 2008) e eficácia em ambientes de P\&D e inovação (PRAJOGO; HONG, 2008).

\subsection{TQM E INOVAÇÃO}

Devido à turbulência econômica existente nos mercados, as organizações têm percebido a inovação como fator estrategicamente determinante para a obtenção de novas oportunidades de negócio (KIM; KUMAR; KUMAR, 2012), bem como para a sobrevivência empresarial e competitiva no longo prazo (SANTOS-VIJANDE; ÁLVAREZ-GONZÁLEZ, 2007). 
Todavia, é necessário desenvolver novas pesquisas que busquem relacionar o TQM à inovação (PRAJOGO; SOHAL, 2008), na tentativa de identificar dimensões até então não percebidas (KIM; KUMAR; KUMAR, 2012; PERDOMO-ORTIZ; GONZÁLEZ-BENITO; GALENDE, 2006) por meio de estudos empíricos mais representativos, que permitam gerar resultados conclusivos.

A literatura apresenta três linhas de pensamento que divergem sobre os aspectos relacionais entre TQM e inovação. A primeira corrente evidencia a existência de relação positiva entre TQM e inovação, afirmando que as organizações que implementam TQM serão bem sucedidas em inovação (PERDOMO-ORTIZ; GONZÁLEZ-BENITO; GALENDE, 2006; MELE; COLURCIO, 2006; SANTOS-VIJANDE; ÁlVAREZ-GONZÁLEZ, 2007; KIM; KUMAR; KUMAR, 2012). No entanto, a linha divergente argumenta que, para algumas variáveis de análise, o TQM impede a inovação (TERZIOVSKI; SAMSON, 1999; HOANG; IGEL; LAOSIRIHONGTHONG, 2006; PINHO, 2008). Uma terceira corrente infere que a relação entre TQM e inovação pode ser parcial, com restrições (ABRUNHOSA; MOURA SÁ, 2008; SADIKOGLU; ZEHIR, 2010).

Diante da divergência de apreciações entre pesquisadores sobre a existência positiva, negativa e/ou parcial entre TQM e inovação, novos estudos devem ser realizados visando a investigar, com maior precisão, os efeitos gerados no desempenho da organização (PEKOVIC; GALIA, 2009) como, por exemplo: maior clareza quanto às dimensões da inovação (produto, processo incremental, radical, tecnológico e não tecnológico) que impactam no TQM (SINGH; SMITH, 2004); necessidade de obtenção de medidas objetivas de desempenho (KAYNAK, 2003); investigação das ligações diretas e indiretas entre as práticas da Gestão da Qualidade e suas relações positivas para a inovação (KIM; KUMAR; KUMAR, 2012).

\subsubsection{Aspectos convergentes entre TQM e inovação}

Pesquisas recentes buscam relacionar o TQM à inovação. Ahire e Ravichandran (2001) enfatizam a necessidade de implantação da ferramenta TQM, uma vez que a mesma difundirá a inovação na empresa. Kim, Kumar e Kumar (2012) desenvolveram um estudo que analisa a associação entre as diferentes práticas de TQM com os cinco tipos de inovação (produto radical, processo radical, produto incremental, processo incremental e inovações 
administrativas). A pesquisa investiga as ligações diretas e indiretas entre as práticas do TQM, demonstrando claramente as relações positivas entre estas práticas e a inovação.

Prajogo e Sohal (2003), por sua vez, analisaram a relação entre as práticas do TQM, performance da qualidade e desempenho da inovação. Os resultados da pesquisa afirmam que o TQM relaciona-se de forma significativa e positivamente com a qualidade do produto (maior magnitude) e com o desempenho da inovação de produtos. Foram identificadas, também, relações causais significativas entre o desempenho da qualidade e inovação (percebendo que o desempenho de um poderia afetar o outro).

Pekovic e Galia (2009) pesquisaram o impacto dos sistemas de qualidade no desempenho inovador, com a finalidade de verificar se a qualidade tem efeito positivo sobre a inovação. $O$ estudo sugere que melhorias significativas no desempenho da inovação sejam realizadas a partir da implantação de sistemas de qualidade. Novas pesquisas devem investigar se as organizações, que desenvolveram as práticas de qualidade, apresentam (ou não) maior impacto sobre o desempenho da firma (em relação às empresas que adotaram de forma tardia). Já Feng et al. (2006) comparam a experiência das organizações na Austrália e Cingapura com relação à multidimensionalidade do TQM e sua relação com o desempenho da qualidade e o desempenho da inovação. Os resultados da pesquisa afirmam que as práticas de TQM apresentam duas dimensões: mecanicista (foco no cliente e gerenciamento de processos) e orgânica (liderança e gestão de pessoas). As dimensões orgânicas estão significativamente relacionadas com o desempenho da inovação, enquanto que as dimensões mecanicistas relacionam-se de forma significativa com o desempenho da qualidade.

Hoang, Igel e Laosirihongthong (2006) investigaram a relação entre as práticas do TQM e o desempenho da inovação no contexto da indústria vietnamita. A pesquisa confirma que o TQM tem impacto positivo sobre a empresa quanto à capacidade de inovação. 0 estudo utilizou duas variáveis para medir a capacidade da empresa para inovar: número de novos produtos/serviços comercializados nos últimos três anos, e percentagem atual do volume de negócios sobre as vendas dos produtos/serviços gerados. Os achados da pesquisa evidenciaram que nem todas as práticas de TQM melhoram a inovação da empresa. Alguns 
elementos que geram impacto positivo quanto ao desempenho inovador da empresa são: liderança e gestão de pessoas, processos e gestão estratégica e organização aberta.

Hill e Collins (2000) analisaram a relação existente entre TQM e BPR (Business Process Reengineering) na mudança organizacional das empresas por meio da melhoria incremental e a inovação radical. O estudo foi desenvolvido em seis organizações e identificou que o TQM (gera melhoria incremental) e o BPR (gera inovação radical) são abordagens complementares para a mudança organizacional. O TQM foi visto como um ferramental fundamental para a implantação da mudança no longo prazo. No entanto, é necessário que exista o compromisso com a qualidade, a capacitação dos funcionários, a aprendizagem, a cultura do trabalho em equipe e o apoio da alta administração. A ausência de crise financeira é determinante para sobrevivência do TQM e BPR, uma vez que a escassez de recursos pode comprometer a sobrevivência das ferramentas na organização. Os resultados da pesquisa revelam que a abordagem integrada do TQM e BPR possibilitam a melhoria incremental e inovação radical, contribuindo para um ambiente propício à transformação da firma no longo prazo.

Para Hung et al. (2011), o TQM apresenta efeitos significativos para a aprendizagem organizacional, inovação e desempenho. Contudo, é importante que os gestores fiquem atentos para o baixo grau de compartilhamento de conhecimento e medo dos funcionários em inovar. Um ambiente propício à inovação é aquele que estimula o conhecimento e a aprendizagem dos funcionários por meio da melhoria da qualidade, confiança, organização aberta, apoio da alta administração, envolvimento dos funcionários, melhoria contínua e foco no cliente. O resultado disto é a geração de produtos e processos inovadores, principalmente por empresas que trabalham com alta tecnologia.

Colurcio (2009) investigou o papel do TQM como facilitador da criação e exploração do conhecimento organizacional. Para isto, analisou 21 empresas por meio dos seguintes elementos de análise: socialização, externalização, combinação e internalização. Os resultados do estudo revelam que o TQM é uma ferramenta eficaz para a geração de conhecimento, principalmente através do envolvimento de todos os empregados, trabalho em equipe, mecanismos de feedback, comunicação aberta, foco no cliente e estímulo ao empowerment. O TQM pode ser visto como uma abordagem sistemática voltada para a Revista Eletrônica de Estratégia \& Negócios, Florianópolis, v.8, n.3, set./dez. 2015. 
gestão de processos que objetiva a melhoria contínua e desempenho da firma e, quando associado à inovação, proporciona vantagem competitiva no longo prazo.

Young, Charns e Shortell (2001) examinaram a importância do papel dos gestores para a adoção de práticas de gestão inovadora. O estudo foi desenvolvido em hospitais públicos e envolveu a participação de gestores de topo e institucionais. A pesquisa revela que ambos os gestores são determinantes para a adoção de inovações durante a fase inicial de difusão do TQM. Todavia, ao longo do processo de implantação, foi percebido que o gestor de topo possui maior relevância para a implantação de práticas de gestão inovadora (se comparado ao desempenho dos gestores institucionais). Este achado confirma a importância da alta administração como elemento fundamental para a implantação e permanência do TQM na empresa.

Neste sentido, um conjunto de argumentos estabelece relação positiva entre TQM e inovação, sugerindo que as empresas que implantam sistemas de qualidade também melhoram o desempenho em inovação (PRAJOGO; SOHAL, 2003; ABRUNHOSA; MOURA SÁ, 2008; PRAJOGO; HONG, 2008). Assim, o impacto do TQM na inovação depende tanto de um sistema de qualidade específico quanto do tipo de inovação (PEKOVIC; GALIA, 2009).

\subsubsection{Aspectos divergentes entre TQM e inovação}

Nem todas as pesquisas confirmam que a implantação do TQM gera inovação (PRAJOGO; SOHAL, 2001). Alguns autores afirmam que o TQM pode dificultar a inovação (KIM; MARBOUGNE, 1999; WIND; MAHAJAN, 1997) ou ter relações parciais como, por exemplo: desempenho da inovação e práticas do TQM; desempenho do empregado e práticas do TQM; e práticas do TQM e desempenho da empresa (SADIKOGLU; ZEHIR, 2010). Portanto, nem todas as práticas do TQM são particularmente forte indicadores de desempenho, dificultando, assim, estabelecer um consenso entre os reais fatores que impactam no TQM (SAMSON; TERZIOVSKI, 1999).

Terziovski e Samson (1999) testaram a força da relação entre as práticas de TQM e o desempenho organizacional (com e sem co-variáveis), tamanho da empresa, tipo de indústria e certificação ISO 9000. O intuito da pesquisa foi investigar se as práticas do TQM provocam efeito significativamente positivo sobre a performance da organização. Os Revista Eletrônica de Estratégia \& Negócios, Florianópolis, v.8, n.3, set./dez. 2015. 
resultados da pesquisa afirmam que o TQM tem efeito significativamente positivo sobre o desempenho operacional e de negócios, relações no trabalho e satisfação do cliente. No entanto, existem diferenças significativas na relação entre TQM e o desempenho organizacional em todos os setores da indústria e empresas de diferentes tamanhos, particularmente sobre as taxas de defeito, custos de garantia e inovação de novos produtos. O estudo não garante que o TQM irá, certamente, produzir rentabilidade superior em organizações com maior qualidade de produtos e serviços, existindo, seguramente, organizações que conseguem bons retornos sem TQM.

\section{PROCEDIMENTOS METODOLÓGICOS}

Este trabalho caracteriza-se como uma revisão sistemática da literatura, uma vez que buscou realizar a revisão de 39 publicações internacionais acerca das temáticas TQM e inovação, conforme preceituam Stuart et al. (2002), Wolfswinkel, Furtmueller e Wilderom (2013) e Rowe (2014). A revisão sistemática da literatura tem a finalidade de produzir, de forma mais rigorosa, uma revisão por meio da análise mais profunda de publicações originais (WOLFSWINKEL; FURTMUELLER; WILDEROM, 2013). O objetivo principal deste estudo é compreender, por meio de um ensaio teórico, a relação entre TQM e inovação, com o intuito de gerar insights e proposições teóricas. Para isso foram analisados 16 dos 20 principais artigos obtidos através da base de dados Scopus. Optou-se por esta base de dados pelo fato de a mesma ser considerada um metabuscador.

A palavra-chave utilizada na pesquisa foi TQM, tendo sido selecionado o critério título do artigo (Article Title) juntamente com a palavra Innovation, por meio do critério palavras-chave (Keywords). O número total de artigos relacionados na base de dados do Scopus, na primeira etapa, foi de 73 documentos. A segunda etapa consistiu na restrição da pesquisa pela área de conhecimento (Business, Management and Acconunting), bem como do tipo do documento (Article), chegando ao número total de 31 textos relacionados aos temas investigados (TQM e Inovação). Tendo em vista o número de artigos analisados (16 documentos), o percentual de análise do ensaio teórico abrangeu 51,61\% dos documentos relacionados na segunda etapa da pesquisa. 
A terceira etapa consistiu na seleção dos artigos pelo número de citações (Cited By). Este critério teve a finalidade de obter os artigos mais citados pela base de dados Scopus. A quarta etapa consistiu na seleção e download dos 20 artigos mais citados conforme critérios de análise já informados anteriormente. A quinta etapa envolveu a leitura prévia do resumo, palavras-chave e considerações finais, com o objetivo de verificar a relevância e foco do artigo (critério utilizado para escolha dos 16 artigos analisados). Posteriormente, os documentos selecionados foram lidos na íntegra. A etapa final consistiu na análise e discussão dos resultados da pesquisa, conforme apresentado na próxima seção.

Com o objetivo de ampliar ainda mais a pesquisa, foram analisados 23 artigos relacionados aos temas TQM e inovação, por meio da análise reversa dos documentos investigados. Para isso foi realizada uma pesquisa adicional nos principais periódicos da área de produção e qualidade, tendo sido decisiva para a elaboração do estudo. Assim, o total de artigos analisados nesta pesquisa foi de 39 publicações (Apêndice A).

\section{RESULTADOS E DISCUSSÕES DA PESQUISA}

Com base no referencial teórico analisado, pode-se perceber a existência de relação (positiva, negativa e/ou parcial) entre as práticas do TQM e inovação. No entanto, notou-se a ausência de estudos conclusivos envolvendo a análise das práticas de TQM associadas aos cinco tipos de inovação (produto incremental, produto radical, processo incremental, processo radical e administrativa), existindo, portanto, necessidade de novas pesquisas. Essa constatação vem ao encontro do que relatam Kim, Kumar e Kumar (2012). A seguir, serão discutidas as principais práticas de TQM, bem como as proposições teóricas acerca da relação entre TQM e inovação.

\subsection{SUPORTE DA ALTA ADMINISTRAÇÃO}

O compromisso da alta administração pode melhorar a satisfação dos clientes. Quando a alta administração estabelece metas de qualidade para a satisfação dos clientes, os funcionários priorizam recursos e ações para atingir os objetivos traçados (KIM; KUMAR; KUMAR, 2012) por meio da aplicação de novos princípios e ferramentas da qualidade (FLYNN; SCHROEDER; SAKAKIBARA, 1994). Para isto é necessário que a alta administração proporcione suporte aos funcionários, promovendo o comprometimento da equipe e Revista Eletrônica de Estratégia \& Negócios, Florianópolis, v.8, n.3, set./dez. 2015. 
treinamento (BUNNEY; DALE, 1997), visando à implantação bem sucedida do TQM na empresa (KAYNAK, 2003).

P1: O suporte da alta administração é essencial para o TQM.

\subsection{ENVOLVIMENTO DO EMPREGADO}

É decisivo para o sucesso de uma organização inovadora, pois fortalece os canais de comunicação (PRAJOGO; SOHAL, 2001, 2003). O empregado deve perceber como seu trabalho se encaixa nas metas e estratégias para melhorar o desempenho organizacional, proporcionando maior envolvimento na resolução dos problemas, consciência para a qualidade, esforço para melhoria do desempenho, e melhor gestão de produtos e processos (KIM; KUMAR; KUMAR, 2012). Para que haja a medição eficaz, a disponibilidade e uso de dados/informações de qualidade, é preciso que a organização detenha um quadro de funcionários qualificados visando à tomada de decisão e, consequentemente, à implantação do TQM (KAYNAK, 2003).

P2: O envolvimento dos empregados é determinante para o TQM.

\subsection{GESTÃO DE PROCESSOS}

A gestão de processos concentra-se no processo de fabricação, devendo funcionar conforme planejado, ou seja, sem avarias, com materiais na quantidade correta, equipamentos com manutenção, ferramental apropriado, etc. A gestão de processos precisa garantir que a variabilidade dos produtos esteja dentro dos limites aceitáveis (FLYNN; SCHROEDER; SAKAKIBARA, 1994). Para isto é necessário que os funcionários atuem junto aos processos da organização, visando à melhoria contínua, à aprendizagem e à gestão do conhecimento (SAMSON; TERZIOVSKI, 1999).

P3: A gestão de processos está positivamente relacionada com a melhoria contínua, aprendizagem e gestão do conhecimento.

\subsection{FOCO NO CLIENTE}

Incentiva as organizações a procurarem suprir constantemente as necessidades e as expectativas dos clientes. Leva as organizações a tornarem-se inovadoras em termos de Revista Eletrônica de Estratégia \& Negócios, Florianópolis, v.8, n.3, set./dez. 2015. 
desenvolvimento e introdução de novos produtos. O foco no cliente melhora o atendimento aos clientes por meio da ligação entre as necessidades dos consumidores e a inovação (PRAJOGO; SOHAL, 2001, 2003). Empresas inovadoras com foco no cliente são pró-ativas às necessidades dos clientes (BON; MUSTAFA, 2013). Empresas que implantam TQM precisam explorar e encontrar maneiras de servir às necessidades e expectativas dos clientes (HOANG; IGEL; LAOSIRIHONGTHONG, 2006). Assim, o foco no cliente é o principal subjacente na filosofia TQM (SAMSON; TERZIOVSKI, 1999).

P4: O foco no cliente direciona o TQM.

\subsection{TRABALHO EM EQUIPE}

"O trabalho em equipe evita a divisão do trabalho, favorece a aprendizagem em grupo (tendo um maior efeito sobre a organização do que a aprendizagem individual) e as pessoas que aprendem em grupo motivam umas as outras a continuar" (SHIBA; GRAHAM; WALDEN, 1997, p. 190). Para Shiba, Grahan e Walden (1997, p. 207), "O desenvolvimento da equipe não é função do tempo, mas função dos gatilhos de desenvolvimento, traduzidos por entusiasmo e comunicação; incentivo ao estudo; oportunidade de aplicação; e sucesso e reconhecimento".

P5: O trabalho em equipe motiva os funcionários para o alcance dos objetivos do TQM.

\subsection{INFORMAÇÃO E ANÁLISE}

Os gestores devem tomar decisões com base na análise de dados e informações relevantes. Os gestores de um ambiente voltado para a Qualidade Total devem disponibilizar informações para todos os usuários-chave, incluindo colaboradores e fornecedores, visando à eficiência e inovação organizacional (SADIKOGLU; ZEHIR, 2010). Samson e Terziovski (1999) sugerem que as organizações com TQM que constantemente coletam e analisam informações serão mais bem sucedidas do que as que não a fazem (neste último caso, podese até inibir o desempenho organizacional).

P6: A informação e análise são fundamentais para a tomada de decisão dos gestores. 


\subsection{MELHORIA CONTÍNUA}

O TQM busca a melhoria contínua (KAYNAK, 2003). A melhoria contínua incentiva a mudança e o pensamento criativo na forma como o trabalho é realizado e organizado (PRAJOGO; SOHAL, 2001, 2003). Refere-se à interminável procura por melhorias e desenvolvimento de processos visando a encontrar melhores métodos de conversão de inputs em outputs. Em um ambiente de Qualidade Total, os processos de trabalho devem ser revistos e melhorados constantemente (SADIKOGLU; ZEHIR, 2010), pretendendo o surgimento de uma filosofia de gestão baseada na melhoria contínua de produtos e processos (PERDOMO-ORTIZ; GONZÁLEZ-BENITO; GALENDE, 2006).

P7: A melhoria contínua interfere no desempenho do TQM.

\subsection{TREINAMENTO}

"Em regra, o treinamento das empresas é inadequado" (SHIBA; GRAHAM; WALDEN, 1997, p. 232). O treinamento da força de trabalho deve ser contínuo, auxiliando os funcionários na descoberta de formas inovadoras para a organização (KAYNAK, 2003). Um ambiente voltado para a qualidade é aquele que propicia a qualificação e desenvolvimento de habilidades e competências relacionadas às ferramentas e técnicas necessárias para a implantação do TQM (SADIKOGLU; ZEHIR, 2010).

P8: O treinamento é a base para implantação do TQM.

\subsection{GESTÃO DA QUALIDADE DE FORNECEDORES}

É a base para a aquisição de peças e materiais com qualidade (KAYNAK, 2003), sendo considerado um aspecto importante para a melhoria da qualidade, consequentemente dos processos internos (AHIRE; RAVICHANDRAN, 2001) e externos. Somente a partir da seleção e certificação dos fornecedores e da avaliação e respostas aos requisitos dos clientes é que a organização caminhará para a melhoria da gestão da qualidade de fornecedores, elemento essencial para a implantação do TQM na empresa (PERDOMO-ORTIZ, GONZÁLEZ-BENITO; GALENDE, 2006). 
P9: A Gestão da Qualidade de Fornecedores interfere nos processos internos e externos do TQM.

\subsection{INOVAÇÃO INCREMENTAL DE PRODUTO}

A inovação é sujeita a um produto ou a um processo (KIM; KUMAR; KUMAR, 2012). A inovação de produto é uma nova tecnologia ou a combinação de tecnologias introduzidas no mercado com a finalidade de atender a demanda de um usuário ou uma necessidade de mercado (UTTERBACK; ABERNATHY, 1975). A inovação [incremental] de produto pode ser classificada com base no grau de novidade do produto para o mercado (PRAJOGO; SOHAL, 2001). A inovação incremental de produto está positivamente relacionada com a introdução de produtos/serviços, visando à obtenção de novas funcionalidades, melhorias e benefícios para a tecnologia existente no mercado (KIM; KUMAR; KUMAR, 2012). O TQM tende a incentivar o desenvolvimento de novos produtos por meio de melhorias para a qualidade (HOANG; IGEL; LAOSIRIHONGTHONG, 2006; PEKOVIC; GALIA, 2009) e inovações incrementais (SINGH; SMITH, 2004), tendo em vista atender às demandas de mercado (PRAJOGO; SOHAL, 2001).

P10a: O TQM está relacionado positivamente com a inovação incremental de produto.

\subsection{INOVAÇÃO INCREMENTAL DE PROCESSO}

A inovação de processo está relacionada positivamente com as alterações/mudanças na forma que uma firma produz produtos/serviços, interferindo diretamente no processo de produção, na produtividade e na eficiência das atividades produtivas da empresa (KIM; KUMAR; KUMAR, 2012). A inovação de processo deve considerar as mudanças na forma como os produtos/serviços são produzidos, resultando tanto na possibilidade de produzir grandes quantidades de produção com os mesmos recursos ou para obter produtos/serviços com níveis mais elevados de desempenho (ABRUNHOSA; MOURA SÁ, 2008). Alguns estudos não evidenciam resultados significativos entre TQM e inovação (PINHO, 2008) devido à ausência de recursos necessários à melhoria contínua, elemento essencial para a obtenção de inovação incremental (SINGH; SMITH, 2004; PINHO, 2008; KIM; KUMAR; KUMAR, 2012). 
P10b: O TQM está relacionado positivamente com a inovação incremental de processo.

\subsection{INOVAÇÃO RADICAL DE PRODUTO}

A inovação radical de produto é definida como aquela associada à introdução de produtos/serviços que incorporam uma nova tecnologia, substancialmente diferente da atualmente utilizada (KIM; KUMAR; KUMAR, 2012). A inovação radical está associada com a estratégia desenvolvida pela empresa, sendo considerada diretamente proporcional ao risco, devido à complexidade técnica do produto e às incertezas do mercado (PRAJOGO; SOHAL, 2001; KIM; KUMAR; KUMAR, 2012). Reconhecer o grau de inovação radical é um fator relevante, pois permite estabelecer os determinantes da inovação e os tipos de recursos necessários a serem utilizados (SANTOS-VIJANDE; ÁLVAREZ-GONZÁLEZ, 2007). A relação positiva entre práticas de Gestão da Qualidade e inovação estimula o surgimento de diferentes tipos de inovação. No entanto, estudos futuros precisam gerar melhor compreensão a respeito da relação positiva entre TQM e inovação radical de produto, tendo em vista a contribuição para a implantação da mudança no longo prazo (HILL; COLLINS, 2000; KIM; KUMAR; KUMAR, 2012).

P10c: O TQM está relacionado positivamente com a inovação radical de produto.

\subsection{INOVAÇÃO RADICAL DE PROCESSO}

Inovação radical é resultante da exploração de novos conhecimentos (DERBYSHIRE, 2014) e competências (ZHOU; LI, 2007), visando à substancial transformação de produtos e serviços (BIEDENBACH; MÜLLER, 2012). O gradual processo de inovação incremental pode contribuir para o processo de ruptura na organização, relacionado principalmente com a inovação radical. Por este motivo, o TQM apresenta elementos que contribuem para o desenvolvimento da inovação radical, uma vez que é preciso mudar a cultura e a mentalidade das pessoas para posterior implantação da inovação radical (SANTOS-VIJANDE; ÁLVAREZ-GONZÁLEZ, 2007; KIM; KUMAR; KUMAR, 2012; BIEDENBACH; MÜLLER, 2012; DERBYSHIRE, 2014). Neste sentido, é preciso que a organização prepare-se, inicialmente, desenvolvendo boas práticas de TQM para que, posteriormente, obtenha a inovação radical de processos. Um exemplo disso é a relação entre TQM e BRP. A implantação da TQM é 
fundamental para o surgimento da BRP (prática necessária para a geração de inovação radical) (HILL; COLLINS, 2000).

P10d: O TQM está relacionado positivamente com a inovação radical de processo.

\subsection{INOVAÇÃO ADMINISTRATIVA}

A inovação administrativa envolve a estrutura organizacional e dos processos administrativos (DAMANPOUR; GOPALAKRISHNAN, 1998). O TQM é uma inovação administrativa, uma vez que envolve a adoção de práticas visando a uma melhor gestão das organizações (AHIRE; RAVICHANDRAN, 2001). Damanpour e Gopalakrishnan (1998) afirmam que as características estruturais facilitam a adoção de inovações de diferentes tipos e em diferentes fases. As inovações administrativas não fornecem um novo produto/serviço, pois influenciam indiretamente nas atividades básicas de trabalho (SANTOS-VIJANDE; ÁLVAREZGONZÁLEZ, 2007), originam-se a partir do núcleo administrativo e devem respeitar o processo decisório top-down (DAMANPOUR; GOPALAKRISHNAN, 1998).

P10e: O TQM contribui, de forma colaborativa, para a obtenção de inovações administrativas.

Tendo em vista facilitar o desenvolvimento de novas pesquisas relacionadas ao tema investigado, elaborou-se o Apêndice B, que relaciona as proposições ao suporte teórico. A identificação das principais práticas do TQM originou-se a partir do Apêndice C.

\section{CONCLUSÕES}

Este artigo teve o objetivo principal de compreender, por meio de uma revisão sistemática da literatura, a relação entre TQM e inovação, com o intuito de gerar insights e proposições teóricas. A partir disso, pretende-se responder ao seguinte problema de pesquisa: De que forma pode-se estabelecer melhor compreensão teórica sobre a relação entre TQM e inovação? O estudo realizado envolve a análise de cinco dimensões da inovação (produto incremental, produto radical, processo incremental, processo radical, e administrativa), assunto pouco pesquisado na literatura acadêmica. Em regra, estudos anteriores não trazem contribuições quanto à inovação administrativa sob a ótica do TQM; poucos estudos relacionam o elemento trabalho em equipe (teamwork) aos cinco tipos de Revista Eletrônica de Estratégia \& Negócios, Florianópolis, v.8, n.3, set./dez. 2015. 
inovações; estudos anteriores demonstram a relação entre a melhoria contínua e a inovação incremental (uma vez que proporciona o pensamento criativo), no entanto, não se aprofundam na relação entre o TQM e inovação radical.

Constatou-se que TQM e inovação apresentam mais aspectos convergentes do que divergentes. É importante perceber que nem sempre as empresas que possuem TQM geram inovações. Todavia, o ambiente organizacional torna-se mais propício às inovações no momento em que a empresa estimula/incentiva a aprendizagem, criatividade, gestão de processos, cultura, mudança de mentalidade, trabalho em equipe e treinamento. As inovações incrementais são tão importantes quanto as inovações radicais, pois aquelas propiciam um ambiente adequado para a obtenção destas, principalmente no longo prazo. Desta forma, uma organização voltada para as práticas do TQM torna-se um ambiente mais fértil para o surgimento de inovações.

Por meio dos Apêndices A, B e C é possível desenvolver novas pesquisas. Sugere-se seu uso com o intuito de auxiliar acadêmicos e pesquisadores no aprofundamento da análise das relações existentes entre as práticas do TQM e os cinco tipos de inovações. Neste sentido, novos trabalhos precisam ser desenvolvidos no intuito de continuar a investigação em relação ao tema proposto. Sendo assim, por meio desta pesquisa, foi possível identificar algumas sugestões para estudos futuros, tais como: aplicação do modelo teórico proposto como base na Modelagem de Equações Estruturais; é importante que seja realizada uma pesquisa de corte longitudinal pelo fato de a maioria dos estudos anteriores terem sido de corte transversal; tendo em vista maior aderência do modelo, sugere-se que o mesmo seja testado, inicialmente, em um grupo homogêneo de empresas (de um mesmo setor e porte, por exemplo); estudos empíricos sobre TQM e inovação devem ser realizados visando a suprir as lacunas existentes na literatura; o modelo proposto poderia ter analisado, também, a relação entre as práticas do TQM e a performance da inovação, podendo ser objeto de investigação em estudos futuros; realização de pesquisas sobre a multidimensionalidade do TQM (aspecto interno e externo); uso de variável mediadora no modelo proposto; analisar, com maior profundidade, a relação das práticas do TQM de forma direta e indireta em relação aos cinco tipos de inovação; e ampliação da pesquisa em um maior número de base de dados (a exemplo da Emerald, Web of Science, Science Direct, Sage, Springer, etc.). 


\section{REFERÊNCIAS}

ABRUNHOSA, A.; MOURA SÁ, P. Are TQM principles supporting innovation in the Portuguese footwear industry? Technovation, v. 28, n. 4, p. 208-221, 2008.

AGARWAL, R.; GREEN, R.; BROWN, P. J.; RANDHAWA, K. Determinants of quality management practices: an empirical study of New Zealand manufacturing firms. International Journal of Production Economics, v. 142, n. 1, p. 130-145, 2013.

AHIRE, S. L.; RAVICHANDRAN, T. An innovation diffusion model of TQM implementation. IEEE Transactions on Engineering Management, v. 48, n. 4, p. 445-464, 2001.

ATUAHENE-GIMA, K. Market orientation and innovation. Journal of Business Research, v. 35, n. 2, p. 93-103, 1996.

BIEDENBACH, T.; MÜLLER, R. Absorptive, innovative and adaptive capabilities and their impact on project and project portfolio performance. International Journal of Project Management, v. 30, n. 5, p. 621-635, 2012.

BON, A. T.; MUSTAFA, E. M. A. Impact of Total Quality Management on innovation in service organizations: literature review and new conceptual framework. Procedia Engineering, v. 53, p. 516-529, 2013.

BUNNEY, H. S.; DALE, B. G. The implementation of quality management tools and techniques: A study. The TQM Magazine, v. 9, n. 3, 183-189, 1997.

CALVO-MORA, A.; PICÓN, A.; RUIZ, C.; CAUZO, L. The relationships between soft-hard TQM factors and key business results. International Journal of Operations \& Production Management, v. 34, n. 1, p. 115-143, 2014.

COLURCIO, M. TQM: a knowledge enabler? The TQM Magazine, v. 21, n. 3, p. 236-248, 2009.

DAMANPOUR, F.; GOPALAKRISHNAN, S. Theories of organizational structure and innovation adoption: the role of environmental change. Journal of Engineering and Technology Management, v. 15, n. 1, p. 1-24, 1998.

DEMING, W. E. Qualidade: a revolução da administração. Rio de Janeiro: Saraiva, 1999.

DERBYSHIRE, J. The impact of ambidexterity on enterprise performance: Evidence from 15 countries and 14 sectors. Technovation, v. 34, n. 10, p. 574-581, 2014.

EHIGIE, B. O.; MCANDREW, E. B. Innovation, diffusion and adoption of quality management (TQM). Management Decision, v. 43, n. 6, p. 925-940, 2005.

FEIGENBAUM, A. V. Controle da qualidade total. 4 v. São Paulo: Makron Books, 1994.

FENG, J.; PRAJOGO, D. I.; TAN, K. C.; SOHAL, A. S. The impact of TQM practices on performance: a comparative study between Australian and Singaporean organizations.

European Journal of Innovation Management, v. 9, n. 3, p. 269-278, 2006.

Revista Eletrônica de Estratégia \& Negócios, Florianópolis, v.8, n.3, set./dez. 2015. 
FLYNN, B. B.; SCHROEDER, R. G.; SAKAKIBARA, S. A framework for quality management research and an associated measurement instrument. Journal of Operations Management, v. 11, n. 4, p. 339-366, 1994.

FOTOPOULOS, C. B.; PSOMAS, E. L. The impact of "soft" and "hard" TQM elements on quality management results. International Journal of Quality \& Reliability Management, v. 26, n. 2, p. 150-163, 2009.

HILL, F.; COLLINS, L. K. The roles of TQM and BPR in organisational change strategies: a case study investigation. International Journal of Quality \& Realiability Management, v. 17, n. 6, p. $614-635,2000$.

HOANG, D. T.; IGEL, B.; LAOSIRIHONGTHONG, T. The impact of total quality management on innovation: Findings from a developing country. International Journal of Quality \& Reliability Management, v. 23, n. 9, p. 1092-1117, 2006.

HUNG, R. Y. Y.; LIEN, B. Y.; YANG, B.; WU, C.; KUO, Y. Impact of TQM and organizational learning on innovation performance in the high-tech industry. International Business Review, v. 20, n. 2, p. 213-225, 2011.

JURAN, J. M. Juran na liderança pela qualidade. 2.ed. São Paulo: Pioneira, 1993.

KAYNAK, $\mathrm{H}$. The relationship between total quality management practices and their effects on firm performance. Journal of Operations Management, v. 21, n. 4, p. 405-435, 2003.

KIM, D.; KUMAR, V.; KUMAR, U. Relationship between quality management pratices and innovation. Journal of Operations Management, v. 30, n. 4, p. 295-315, 2012.

KIM, W. C.; MARBOUGNE, R. Strategy, value innovation, and the knowledge economy. Sloan Management Review, v. 2, spring, p. 41-54, 1999.

LAGROSEN, Y.; LAGROSEN, S. The effects of quality management: a survey of Swedish quality professionals. International Journal of Operations \& Production Management, v. 25, n. 10, p. 940-952, 2005.

LINDERMAN, K.; SCHROEDER, R. G.; ZAHEER, S.; LIEDTKE, C.; CHOO, A. S. Intergrating quality management practices with knowledge creation processes. Journal of Operations Management, v. 22, n. 6, p. 589-607, 2004.

MELE, C.; COLURCIO, M. The evolving path of TQM: towards business excellence and stakeholder value. International Journal of Quality \& Reliability Management, v. 23, n. 5, p. 464-489, 2006.

MOLINA, L. M.; LLORÉNS-MONTES, J.; RUIZ-MORENO, A. Relationship between quality management practices and knowledge transfer. Journal of Operations Management, v. 25, n. 3, p. 682-701, 2007.

PEKOVIC, S.; GALIA, F. From quality to innovation: evidence from two french employer surveys. Technovation, v. 29, n. 12, p. 829-842, 2009.

Revista Eletrônica de Estratégia \& Negócios, Florianópolis, v.8, n.3, set./dez. 2015. 
PERDOMO-ORTIZ, J.; GONZÁLEZ-BENITO, J.; GALENDE, J. Total quality management as a forerunner of business innovation capability. Technovation, v. 26, n. 10, p. 1170-1185, 2006.

PINHO, J. C. TQM and performance in small medium enterprises: the mediating effect of customer orientation and innovation. International Journal of Quality \& Reliability Management, v. 25, n. 3, p. 256-275, 2008.

POWELL, T. C. Strategic planning as competitive advantage. Strategic Management Journal, v. 13, p. 551-558, 1992.

POWELL, T. C. Total Quality Management as competitive advantage: a review and empirical study. Strategic Management Journal, v. 16, n. 1, p. 15-37, 1995.

PRAJOGO, D. I.; HONG, S. W. The effect of TQM on performance in R\&D environments: A perspective from South Korean firms. Technovation, v. 28, n. 12, p. 855-863, 2008.

PRAJOGO, D. I.; SOHAL, A. S. The relationship between TQM practices, quality performance, and innovation performance: An empirical examination. Internacional Journal of Quality and Reliability Management, v. 20, n. 8, p. 901-918, 2003.

PRAJOGO, D. I.; SOHAL, A. S. The integration of TQM and technology/R\&D management in determining quality and innovation performance. Omega, v. 34, n. 3, p. 296-312, 2006.

PRAJOGO, D. I.; SOHAL, A. S. TQM and innovation: a literature review and research framework. Technovation, v. 21, n. 9, p. 539-558, 2001.

PRAJOGO, D. I.; SOHAL, A. S. The multidimensionality of TQM practices in determining quality and innovation performance: an empirical examination. Technovation, v. 24, n. 6, p. 443-453, 2004.

ROWE, F. What literature review is not: diversity, boundaries and recommendations. European Journal of Information Systems, v. 23, n. 3, p. 241-253, 2014.

SADIKOGLU, E.; ZEHIR, C. Investigating the effects of innovation and employee performance on the relationship between total quality management practices and firm performance: An empirical study of Turkish firms. International Journal of Production Economics, v. 127, n. 1, p. 13-26, 2010.

SAMSON, D.; TERZIOVSKI, M. The relationship between total quality management practices and operational performance. Journal of Operations Management, v. 17, n. 4, p. 393-409, 1999.

SANTOS-VIJANDE, M. L.; ÁLVAREZ-GONZÁLEZ, L. Innovativeness and organizational innovation in total quality oriented firms: The moderating role of market turbulence. Technovation, v. 27, n. 9, p. 514-532, 2007.

SHAN, S.; ZHAO, Q.; HUA, F. Impact of quality management practies on the knowledge creation process: the chinese aviation firm perspective. Computers \& Industrial Engineering, v. 64, n. 1, p. 211-223, 2013. 
SHIBA, S.; GRAHAM, A.; WALDEN, D. TQM: quatro revoluções na Gestão da Qualidade. Porto Alegre: Artes Médicas, 1997.

SILA, I.; EBRAHIMPOUR, M. An investigation of the total quality management survey based research published between 1989 and 2000: a literature review. International Journal of Quality \& Reliability Management, v. 19, n. 7, p. 902-970, 2002.

SINGH, P. J.; POWER, D.; CHUONG, S. C. A resource dependence theory perspective of ISO 9000 in managing organization environment. Journal of Operations Management, v. 29, n. 1-2, p. 49-64, 2011.

SINGH, P. J.; SMITH, A. F. R. Relationship between TQM and innovation: an empirical study. Journal of Manufacturing Technology Management, v. 15, n. 5, p. 394-401, 2004.

STUART, I.; MCCUTCHEON, D.; HANDFIELD, R.; MCLACHLIN, R.; SAMSON, D. Effective case research in operations management: a process perspective. Journal of Operations Management, v. 20, n. 5, p. 419-433, 2002.

TERZIOVSKI, M.; SAMSON, D. The link between total quality management practice and organisational performance. Internacional Journal of Quality and Reliability Management, v. 16, n. 3, p. 226-237, 1999.

TONDOLO, V. A. G.; BITENCOURT, C. C. Compreendendo as capacidades dinâmicas a partir de seus antecedentes, processos e resultados. Brazilian Business Review, v. 11, n. 5, p. 124147, 2014.

UTTERBACK, J. M.; ABERNATHY, W. J. A dynamic model of process and product innovation. Omega - The International Journal of Management Science, v. 3, n. 6, p. 639-656, 1975.

VOUZAS, F.; PSYCHOGIOS, A. G. Assessing manager's awareness of TQM. The TQM Magazine, v. 19, n. 1, p. 62-75, 2007.

WIND, J.; MAHAJAN, V. Issues and opportunities in new product development: an introduction to the special issue. Journal of Marketing Research, v. 34, n. 1, p. 1-12, 1997.

WOLFSWINKEL, J. F.; FURTMUELLER, E.; WILDEROM, C. P. M. Using grounded theory as a method for rigorously reviewing literature. European Journal of Information Systems, v. 22, n. 1, p. 45-55, 2013.

YOUNG, G. J.; CHARNS, M. P.; SHORTELL, S. M. Top manager and network effects on the adption of innovative management practices: a study of TQM in a public hospital system. Strategic Management Journal, v. 22, n. 10, p. 935-951, 2001.

ZEHIR, C.; ERTOSUN, Ö. G.; ZEHIR, S.; MÜCELDILLI, B. Total Quality Management practices effects on quality performance and innovative performance. Procedia - Social and Behavioral Sciences, v. 41, p. 273-280, 2012.

ZHOU, K. Z.; LI, C. How does strategic orientation matter in Chinese firms? Asia Pacific Journal of Management, v. 24, n. 4, p. 447-466, 2007. 
http://portaldeperiodicos.unisul.br/index.php/EeN/index

\section{APÊNDICE A - Principais autores e periódicos pesquisados}

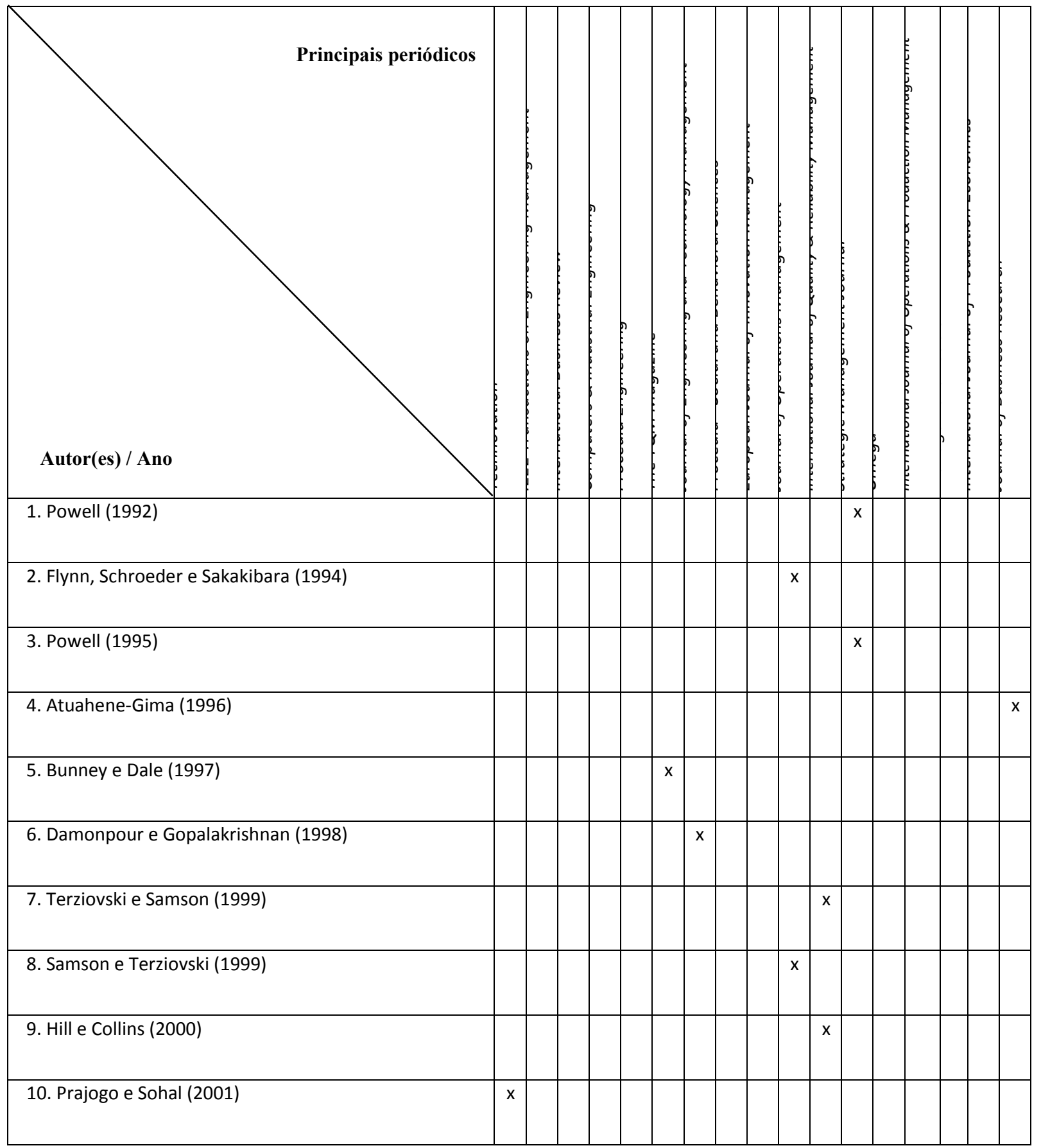
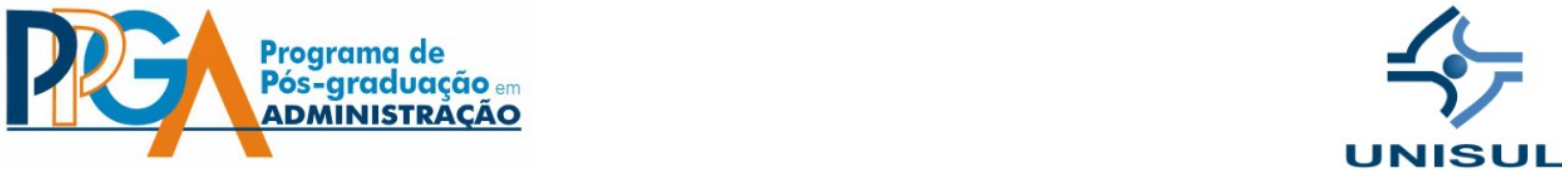


\begin{tabular}{|c|c|c|c|c|c|c|c|c|c|c|c|c|c|c|c|}
\hline 11. Ahire e Ravichandran (2001) & & $\mathrm{x}$ & & & & & & & & & & & & & \\
\hline 12. Young, Charns e Shortell (2001) & & & & & & & & & & & $\mathrm{x}$ & & & & \\
\hline 13. Sila e Ebrahimpour (2002) & & & & & & & & & & $\mathrm{x}$ & & & & & \\
\hline 14. Kaynak (2003) & & & & & & & & & $\mathrm{x}$ & & & & & & \\
\hline 15. Prajogo e Sohal (2003) & & & & & & & & & & $x$ & & & & & \\
\hline 16. Linderman et al. (2004) & & & & & & & & & $x$ & & & & & & \\
\hline 17. Lagrosen e Lagrosen (2005) & & & & & & & & & & & & & $\mathrm{x}$ & & \\
\hline 18. Ehigie e McAndrew (2005) & & & & & & & & & & & & & & $x$ & \\
\hline 19. Hoang, Igel e Laosirihongthong (2006) & & & & & & & & & & $\mathrm{x}$ & & & & & \\
\hline 20. Prajogo e Sohal (2006) & & & & & & & & & & & & $\mathrm{x}$ & & & \\
\hline 21. Feng et al. (2006) & & & & & & & & $\mathrm{x}$ & & & & & & & \\
\hline 22. Mele e Colurcio (2006) & & & & & & & & & & $x$ & & & & & \\
\hline 23. Perdomo-Ortiz, González-Benito e Galende (2006) & $\mathrm{x}$ & & & & & & & & & & & & & & \\
\hline 24. Molina, Lloréns-Montes e Ruiz-Moreno (2007) & & & & & & & & & $x$ & & & & & & \\
\hline 25. Santos-Vijande e Álvarez-González (2007) & $\mathrm{x}$ & & & & & & & & & & & & & & \\
\hline 26. Vouzas e Psychogios (2007) & & & & & & $x$ & & & & & & & & & \\
\hline 27. Abrunhosa e Moura e Sá (2008) & $\mathrm{x}$ & & & & & & & & & & & & & & \\
\hline 28. Prajogo e Sohal (2008) & $\mathrm{x}$ & & & & & & & & & & & & & & \\
\hline 29. Pinho (2008) & & & & & & & & & & $\mathrm{x}$ & & & & & \\
\hline 30. Colurcio (2009) & & & & & & $x$ & & & & & & & & & \\
\hline 31. Fotopoulos e Psomas (2009) & & & & & & & & & & $\mathrm{x}$ & & & & & \\
\hline 32. Sadikoglu e Zehir (2010) & & & & & & & & & $x$ & & & & & & \\
\hline 33. Hung et al. (2011) & & & $x$ & & & & & & & & & & & & \\
\hline
\end{tabular}

Revista Eletrônica de Estratégia \& Negócios, Florianópolis, v.8, n.3, set./dez. 2015. 


\begin{tabular}{|l|l|l|l|l|l|l|l|l|l|l|l|l|l|l|l|l|l|}
\hline 34. Kim, Kumar e Kumar (2012) & & & & & & & & & & $\mathrm{x}$ & & & & & & & \\
\hline 35. Zehir et al. (2012) & & & & & & & $\mathrm{x}$ & & & & & & & & \\
\hline 36. Bon e Mustafa (2013) & & & & $\mathrm{x}$ & & & & & & & & & \\
\hline 37. Shan, Zhao e Hua (2013) & & & & $\mathrm{x}$ & & & & & & & & & & & \\
\hline 38. Agarwal et al. (2013) & & & & & & & & & & & & & & $x$ & \\
\hline 39. Calvo-Mora et al. (2014) & & & & & & & & & & & & $x$ & & & \\
\hline Frequência & 5 & 1 & 1 & 1 & 1 & 3 & 1 & 1 & 1 & 7 & 8 & 3 & 1 & 2 & 1 & 1 & 1 \\
\hline
\end{tabular}

Fonte: Elaborado pelos autores (2014).

\section{APÊNDICE B - Proposições e suporte teórico}

\begin{tabular}{|c|c|}
\hline Proposições & Suporte Teórico \\
\hline $\begin{array}{l}\text { P1: O suporte da alta administração é } \\
\text { essencial para o TQM. }\end{array}$ & $\begin{array}{l}\text { Flynn, Schroeder e Sakakibara (1994); Powell (1995); Shiba, Graham e } \\
\text { Walden (1997); Samson e Terziovski (1999); Ahire e Ravichandran } \\
\text { (2001); Kaynak (2003); Hoang, Igel e Laosirihongthong (2006); Perdomo- } \\
\text { Ortiz, González-Benito e Galende (2006); Santos-Vijande e Álvarez- } \\
\text { González (2007); Pinho (2008); Bon e Mustafa (2013); Shan, Zhao e Hua } \\
\text { (2013). }\end{array}$ \\
\hline $\begin{array}{l}\text { P2: O envolvimento dos empregados } \\
\text { é determinante para o TQM. }\end{array}$ & $\begin{array}{l}\text { Flynn, Schroeder e Sakakibara (1994); Shiba, Graham e Walden (1997); } \\
\text { Kaynak (2003); Hoang, Igel e Laosirihongthong (2006); Santos-Vijande e } \\
\text { Álvarez-González (2007); Bon e Mustafa (2013); Shan, Zhao e Hua (2013). }\end{array}$ \\
\hline $\begin{array}{l}\text { P3: A gestão de processos está } \\
\text { positivamente relacionada com a } \\
\text { melhoria contínua, aprendizagem e } \\
\text { gestão do conhecimento. }\end{array}$ & $\begin{array}{l}\text { Kaynak (2003); Prajogo e Sohal (2003); Hoang, Igel e Laosirihongthong } \\
\text { (2006); Feng et al. (2006); Mele e Colurcio (2006); Perdomo-Ortiz, } \\
\text { González-Benito e Galende (2006); Prajogo e Sohal (2008); Sadikoglu e } \\
\text { Zehir (2010); Kim, Kumar e Kumar (2012). }\end{array}$ \\
\hline $\begin{array}{l}\text { P4: O foco no cliente direciona o } \\
\text { TQM. }\end{array}$ & $\begin{array}{l}\text { Powell (1995); Shiba, Graham e Walden (1997); Samson e Terziovski } \\
\text { (1999); Ahire e Ravichandran (2001); Kaynak (2003); Prajogo e Sohal } \\
\text { (2003); Hoang, Igel e Laosirihongthong (2006); Santos-Vijande e Álvarez- } \\
\text { González (2007); Prajogo e Sohal (2008); Sadikoglu e Zehir (2010); Bon e } \\
\text { Mustafa (2013); Shan, Zhao e Hua (2013). }\end{array}$ \\
\hline $\begin{array}{l}\text { P5: O trabalho em equipe motiva os } \\
\text { funcionários para o alcance dos }\end{array}$ & Shiba, Graham e Walden (1997); Hoang, Igel e Laosirihongthong (2006); \\
\hline
\end{tabular}

Revista Eletrônica de Estratégia \& Negócios, Florianópolis, v.8, n.3, set./dez. 2015. 
SOBRE A LÓGICA DAS RELAÇÕES ENTRE TQM E INOVAÇÃO: INSIGHTS E PROPOSIÇÕES TEÓRICAS

Rodrigo Marques de Almeida Guerra - Cosmo Severiano Filho [In memoriam] - Vilmar Antônio Gonçalves Tondolo

\begin{tabular}{|c|c|}
\hline objetivos do TQM. & Molina, Lloréns-Montes e Ruiz-Moreno (2007). \\
\hline $\begin{array}{l}\text { P6: A informação e análise são } \\
\text { fundamentais para a tomada de } \\
\text { decisão dos gestores. }\end{array}$ & $\begin{array}{l}\text { Samson e Terziovski (1999); Prajogo e Sohal (2003); Feng et al. (2006); } \\
\text { Hoang, Igel e Laosirihongthong (2006); Prajogo e Sohal (2008); Sadikoglu } \\
\text { e Zehir (2010); Bon e Mustafa (2013). }\end{array}$ \\
\hline $\begin{array}{l}\text { P7: A melhoria contínua interfere no } \\
\text { desempenho do TQM. }\end{array}$ & $\begin{array}{l}\text { Flynn, Schroeder e Sakakibara (1994); Shiba, Graham e Walden (1997); } \\
\text { Ahire e Ravichandran (2001); Mele e Colurcio (2006); Santos-Vijande e } \\
\text { Álvarez-González (2007); Pinho (2008); Sadikoglu e Zehir (2010); Zehir et } \\
\text { al. (2012); Bon e Mustafa (2013). }\end{array}$ \\
\hline $\begin{array}{l}\text { P8: O treinamento é a base para } \\
\text { implantação do TQM. }\end{array}$ & $\begin{array}{l}\text { Powell (1995); Shiba, Graham e Walden (1997); Kaynak (2003); Hoang, } \\
\text { Igel e Laosirihongthong (2006); Molina, Lloréns-Montes e Ruiz-Moreno } \\
\text { (2007); Santos-Vijande e Álvarez-González (2007); Pinho (2008); } \\
\text { Sadikoglu e Zehir (2010); Kim, Kumar e Kumar (2012); Bon e Mustafa } \\
\text { (2013); Shan, Zhao e Hua (2013). }\end{array}$ \\
\hline $\begin{array}{l}\text { P9: A Gestão da Qualidade de } \\
\text { Fornecedores interfere nos processos } \\
\text { internos e externos do TQM. }\end{array}$ & $\begin{array}{l}\text { Shiba, Graham e Walden (1997); Ahire e Ravichandran (2001); Kaynak } \\
\text { (2003); Molina, Lloréns-Montes e Ruiz-Moreno (2007); Sadikoglu e Zehir } \\
\text { (2010); Shan, Zhao e Hua (2013). }\end{array}$ \\
\hline $\begin{array}{l}\text { P10a: O TQM está relacionado } \\
\text { positivamente com a inovação } \\
\text { incremental de produto. }\end{array}$ & $\begin{array}{l}\text { Prajogo e Sohal (2003); Singh e Smith (2004); Feng et al. (2006); Mele e } \\
\text { Colurcio (2006); Hoang, Igel e Laosirihongthong (2006); Prajogo e Sohal } \\
\text { (2008); Pinho (2008); Pekovic e Galia (2009); Kim, Kumar e Kumar (2012); } \\
\text { Bon e Mustafa (2013). }\end{array}$ \\
\hline $\begin{array}{l}\text { P10b: O TQM está relacionado } \\
\text { positivamente com a inovação } \\
\text { incremental de processo. }\end{array}$ & $\begin{array}{l}\text { Prajogo e Sohal (2003); Abrunhosa e Moura Sá (2008); Kim, Kumar e } \\
\text { Kumar (2012); Bon e Mustafa (2013). }\end{array}$ \\
\hline $\begin{array}{l}\text { P10c: O TQM está relacionado } \\
\text { positivamente com a inovação radical } \\
\text { de produto. }\end{array}$ & $\begin{array}{l}\text { Prajogo e Sohal (2001); Santos-Vijande e Álvarez-González (2007); Kim, } \\
\text { Kumar e Kumar (2012). }\end{array}$ \\
\hline $\begin{array}{l}\text { P10d: O TQM está relacionado } \\
\text { positivamente com a inovação radical } \\
\text { de processo. }\end{array}$ & $\begin{array}{l}\text { Hill e Collins (2000); Prajogo e Sohal (2001); Santos-Vijande e Álvarez- } \\
\text { González (2007); Kim, Kumar e Kumar (2012). }\end{array}$ \\
\hline $\begin{array}{l}\text { P10e: O TQM contribui, de forma } \\
\text { colaborativa, para a obtenção de } \\
\text { novas inovações administrativas. }\end{array}$ & $\begin{array}{l}\text { Damanpour e Gopalakrishnan (1998); Hill e Collins (2000); Ahire e } \\
\text { Ravichandran (2001); Santos-Vijande e Álvarez-González (2007); Kim, } \\
\text { Kumar e Kumar (2012); Biedenbach e Müller (2012); Bon e Mustafa } \\
\text { (2013); Derbyshire (2014). }\end{array}$ \\
\hline
\end{tabular}

Fonte: Elaborado pelos autores (2014).

Revista Eletrônica de Estratégia \& Negócios, Florianópolis, v.8, n.3, set./dez. 2015. 


\section{APÊNDICE C - Principais práticas do TQM e inovação}

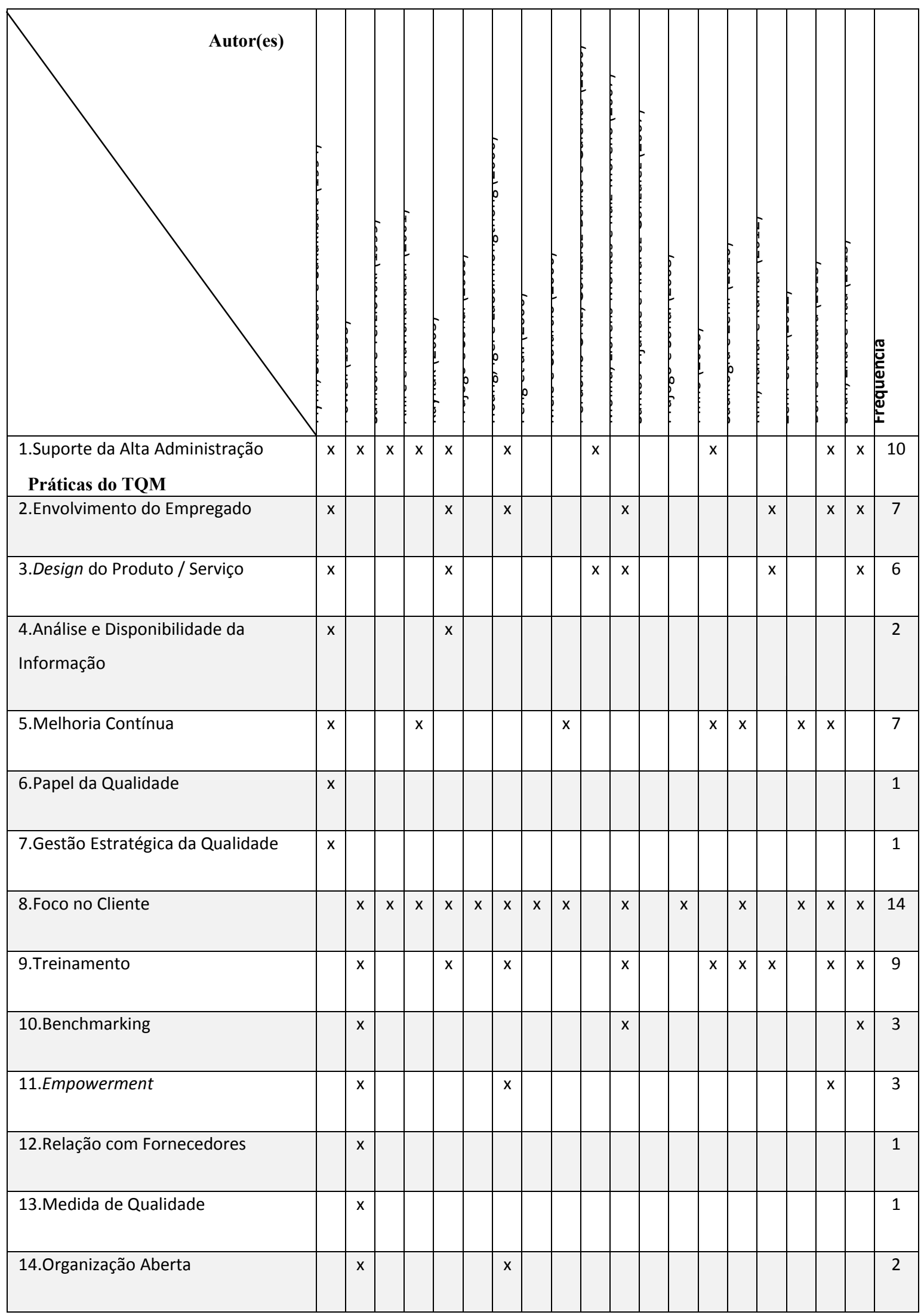

Revista Eletrônica de Estratégia \& Negócios, Florianópolis, v.8, n.3, set./dez. 2015. 


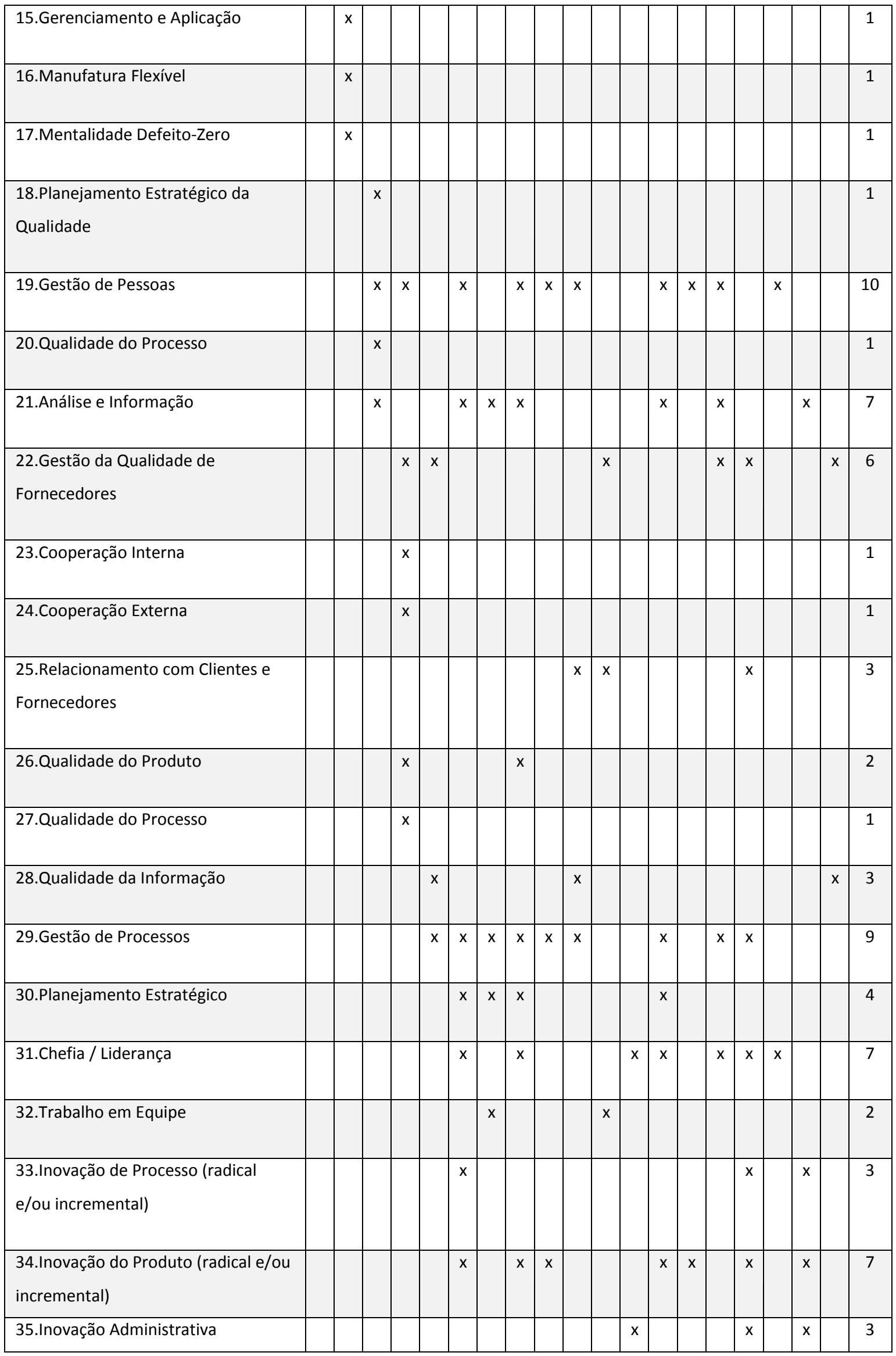

Fonte: Elaborado pelos autores (2014).

Revista Eletrônica de Estratégia \& Negócios, Florianópolis, v.8, n.3, set./dez. 2015. 